\title{
Associations of Physical Activity and Sedentary Time in Primary School Children with Their Parental Behaviors and Supports
}

\author{
Chiaki Tanaka ${ }^{1, *}$, Masayuki Okuda ${ }^{2} \mathbb{(}$, Maki Tanaka $^{3}$, Shigeru Inoue ${ }^{4} \mathbb{D}$ and Shigeho Tanaka ${ }^{5}$ \\ 1 Division of Integrated Sciences, J. F. Oberlin University, Tokyo 194-0294, Japan \\ 2 Department of Environmental Medicine, Graduate School of Science and Engineering, \\ Yamaguchi University, Yamaguchi 755-8505, Japan; okuda@yamaguchi-u.ac.jp \\ 3 Department of Early Childhood Education, Kyoto Bunkyo Junior College, Kyoto 611-0041, Japan; \\ m-tanaka@po.kbu.ac.jp \\ 4 Department of Preventive Medicine and Public Health, Tokyo Medical University, Tokyo 160-8402, Japan; \\ inoue@tokyo-med.ac.jp \\ 5 Department of Nutrition and Metabolism, National Institute of Health and Nutrition, National Institutes of \\ Biomedical Innovation, Health and Nutrition, Tokyo 162-8636, Japan; tanakas@nibiohn.go.jp \\ * Correspondence: c-tanaka@obirin.ac.jp; Tel.: +81-42-797-9145
}

Received: 16 July 2018; Accepted: 7 September 2018; Published: 13 September 2018

check for updates

\begin{abstract}
Background: The associations of objectively evaluated moderate-to-vigorous physical activity (MVPA) and sedentary time between primary school children and their fathers or mothers have not been fully understood. Therefore, we tested the associations in children. Methods: The participants were first to sixth grade boys $(n=166,9.4 \pm 1.6$ years) and girls ( $n=202$, $9.4 \pm 1.6$ years) and their parents (fathers, $n=123$ and mothers, $n=321$ ). MVPA and sedentary time were measured using triaxial accelerometry. The relationship between parental support which was assessed by self-reported questionnaire and children's MVPA was also examined. Results: MVPA in the children was positively correlated with maternal MVPA after adjustment for the children's gender, grade, body mass index z-score, paternal or maternal age, and school $(p<0.001)$. However, paternal or maternal sedentary time and paternal MVPA showed no significant association with sedentary time or MVPA in children. On the other hand, the percentage of MVPA in children who spent more time with their mothers on weekends was significantly lower than those who spent less time $(p=0.034)$. Children whose mothers watched their sports events had a significantly higher percentage of MVPA than those whose mothers did not watch these events $(p=0.008)$. There were no associations between children's MVPA and paternal support. Conclusions: The findings of this study demonstrate the significance of maternal MVPA and support.
\end{abstract}

Keywords: exercise; moderate-to-vigorous physical activity; parental supports; sports; accelerometer

\section{Introduction}

Sufficient physical activity (PA) and a low level of sedentary behavior are important for health in school-aged children and youth [1-3]. A previous systematic review reported longitudinal changes in objectively evaluated total sedentary time in school-aged children and youth [4]. The weighted mean increase in daily sedentary time per year was $5.7 \%$ for boys and $5.8 \%$ for girls, equating to approximately $30 \mathrm{~min}$ of extra daily sedentary time during the year. Recently, Jago et al. [5] reported the changes that occurred in PA and sedentary time of children from the Bristol (UK) B-PROACT1V cohort aged between 5-6 and 8-9 years. The results showed there were similar increases in sedentary time in these girls and boys, with the decrease in moderate-to-vigorous PA (MVPA) being more marked in 
girls [5]. It is therefore desirable to offset these decreases in MVPA and increase in sedentary time by promoting PA and reducing sedentary time in the early years of childhood.

It has been suggested that parents play a critical role in developing and shaping the PA and sedentary behavior of their children through role modelling [6-8]. Previous studies on primary school aged children and their parents have examined the associations between objectively measured PA or sedentary time in parents and their children $[6,7,9]$. However, a recent systematic review pointed out that only a few studies have examined the effect of fathers on children's PA and this relationship remains unclear [10]. A recent longitudinal study in the UK found that there was little evidence that either male or female parent MVPA at 5-6 years of age predicted child MVPA at 8-9 years of age. Similar associations were observed for sedentary time. There is also little evidence that changes in parent MVPA or sedentary time predict changes in MVPA or sedentary time in children, respectively. It is suggested that interventions that aim to increase the activity levels of children by increasing their parent's levels are unlikely to have a marked impact on improving childhood activity at a population level [11]. In this regard, it is unlikely simple strategies that focus on encouraging parents to be active together with their child will be sufficient to increase PA in children [12].

Previous studies have shown that parents can influence the health behavior of their children by engaging in supportive behavior [13-17]. For example, greater parental support for PA was reported to be associated with greater objectively evaluated child PA in UK and USA studies [13-17]. However, the contents of the parental support activities were not consistent between these studies. Moreover, these previous studies analyzed two sub-factors: logistic support and explicit modeling. The relationship between parental support for PA in primary school children and the children's PA should therefore be examined in greater detail. Especially, no previous studies examined the relationships between both mother's and father's support and child's PA. In these previous studies questions on parental support were addressed to only one parent, and the majority was mothers' answers. Thus, the potentially important role of different sex parental support should be examined. Moreover, an association between parental support and sedentary time in children is little known.

The purpose of this study was to examine the associations between objectively evaluated sedentary time and MVPA in primary school children and their fathers or mothers. The relationship between fathers' or mothers' supports and children's MVPA or sedentary time was also examined.

\section{Materials and Methods}

The study was a cross-sectional design that investigated Japanese children and their parents. A total of 166 boys (their 148 mothers and 58 fathers) and 202 girls (their 173 mothers and 65 fathers) from 14 primary schools in urban areas of Tokyo and Kyoto were included in the convenience sample. Flyers were distributed in the schools to invite participants to join the study and all participants and their parents gave their informed consent. The study protocol (receipt number, 12,023) was approved by the Ethical Committee of J. F. Oberlin University. Data for anthropometric measurements, sedentary time, and PA were collected during the school year between June 2012 and January 2015 (June, September, October, and November 2012, on April, October, and November 2013, on November 2014, and on January 2015).

\subsection{Objective Measurement of Sedentary Time and Physical Activity}

A triaxial accelerometer (Active Style Pro HJA-350IT, Omron Healthcare, Kyoto, Japan) with dimensions of $74 \times 46 \times 34 \mathrm{~mm}$ and weight $60 \mathrm{~g}$ including batteries was used to measure sedentary time and PA. The participants wore the accelerometer on the left side of the waist during the school year. The details of the accelerometer are described elsewhere [18]. Briefly, the synthetic acceleration of three axes was calculated using signals before and after high-pass filtering using 10-s Epoch to remove the gravitational acceleration component from the signal. The ratio of unfiltered to filtered acceleration was then calculated to classify the type of PA: ambulatory activities such as walking and running and non-ambulatory activities such as playing games, playing with blocks, tossing a ball, cleaning and 
clearing away. The accelerometer provides metabolic equivalents (METs) [19]. For parents, the METs provided by the accelerometer were used. However, the METs are overestimated for primary school children because the predictive equations used for the Active style Pro accelerometer were established for adults [20]. Therefore, the following conversion equations for primary school children obtained from the results of Hikihara et al. [20] were used: Ambulatory activities, $0.6237 \times$ MET value from the Active style Pro + 0.2411; non-ambulatory activities, $0.6145 \times$ MET value from the Active style Pro +0.5573 .

Sedentary time and MVPA were monitored continuously for 7 days. The participants were requested to wear the accelerometers at all times, except under special circumstances, such as dressing, bathing, or swimming. We analyzed the accelerometer data of children collected between 7:00 and 21:00 to exclude sleep time and to distinguish sedentary time from sleep time. We also excluded sleep time from the accelerometer data of parents using the parents' log sheet. We included days in which the device had been worn for more than $600 \mathrm{~min}(10 \mathrm{~h})$, not including the time elapsed for the above stated unavoidable reasons [21]. Our analysis included participants with data available from at least 2 weekdays and 1 weekend day.

\subsection{Anthropometric Measurements}

For the anthropometric measurement, body height and weight were measured without shoes, but with clothing. We measured some children's clothes, and the average weight was $0.7 \mathrm{~kg}$. The weight of clothing $(0.7 \mathrm{~kg})$ was subtracted from the measured body weight to calculate net body weight on the first day that the students were given accelerometers. This net body weight was then used to calculate body mass index (BMI, $\left.\mathrm{kg} / \mathrm{m}^{2}\right)$. The chronological age was calculated as the difference between the birthdate and the first date of accelerometer assessment [22,23], while the students' calendar age was calculated accurately from the month and year of birth until the first day of measurement.

\subsection{Self-Reported Measures}

Questionnaire data were collected from the parents with their parental behavior evaluated by the following six questions. Q1, "How much time do you spend with your child on weekdays?" $-0,30 \mathrm{~min}$, $1,2,3,4$, or $>5 \mathrm{~h}$; Q2, "How much time do you spend with your child on weekends?" $-0,30 \mathrm{~min}, 1,2,3$, 4 , or $>5$ h; Q3, "How often do you encourage your child to be physically active?-rarely, occasionally, often, or always; Q4, "Do you watch your child's sporting events?"-rarely, occasionally, often, or always; Q5, "Do you think that it is important for you to pay attention to sports?"- -unimportant, somewhat important, important, or very important; and Q6, "Does your family enjoy sports or physical activities as a family recreational activity?"-rarely, occasionally, often, or always. We also asked parents' occupation, work pattern (full-time work, part-time work) and jobs on Saturday and Sunday. Parents who had jobs on Saturday and Sunday were considered as having weekend job duty.

\subsection{Statistical Analysis}

The sedentary time and MVPA for each time period were calculated using METs, in which the average number of weekday or weekend minutes spent in sedentary time $(\leq 1.5 \mathrm{METs})$ and MVPA $(\geq 3.0$ METs) was calculated for each individual. The average and percentage weekly values were then calculated using weighting for 5 weekdays and 2 weekend days (weighted data $=$ (Average for 2 weekdays $\times 5+$ average for 1 weekend day $\times 2) \div 7$ ). PA assessed by the accelerometer was expressed as PA status for ambulatory activity or non-ambulatory activity in MVPA. 
In the questionnaire, responses to Q1 and Q2 were categorized into two groups according to the distribution of each answer. Q3, Q4, and Q6 were categorized into "yes" or "no" according to the answers of "rarely and occasionally" or "often and always". Q5 was categorized into "unimportant", "somewhat important" or "important" according to the answers of "unimportant", "somewhat important" or "important and very important". The associations between children's percentage of MVPA (\%MVPA) or \% sedentary time and their parent's activity or behavior were examined using mixed linear regression models. MVPA and sedentary time were divided by total wear time to obtain \%MVPA and \%sedentary time, respectively. We analyzed the associations between factors of the children's mothers and fathers, separately. Gender, grade, and body mass index z-score of the children were included in the models as confounders. Families nested in the schools were also included as random effects. When the parent's activity was an independent variable, their age was included as a cofounder. As summarized in Figure 1, the initial children's sample comprised 569 participants. Due to missing data including no accelerometer data by the above-mentioned criteria $(n=91)$, revocation of the agreement $(n=8)$, history of conditions affecting PA, such as respiratory disease or heart disease $(n=27)$, no questionnaire data $(n=16)$, different ethnic group $(n=1)$, missing data including no accelerometer data by the criteria of parents $(n=40)$, revocation of the consent of parents $(n=2)$, history of conditions affecting PA of parents $(n=11)$, no questionnaire data of parents $(n=4)$, and pregnancy of the mother $(n=1)$, the final study sample comprised data from 368 children. The initial parents' sample comprised 651 participants. Due to missing data including no accelerometer data, no data from their child $(n=151)$, no above-mentioned criteria $(n=42)$, revocation of the agreement $(\mathrm{n}=10)$, history of conditions affecting PA, such as respiratory disease or heart disease $(n=17)$, no questionnaire data $(n=5)$, different ethnic group $(n=3)$, and pregnancy $(n=1)$, the final study sample comprised data from 422 parents. There was no significant difference in the age, body weight, and body height of the study group and the children who withdrew from the study. There was no significant difference in the age of the study group and the parents who withdrew from the study. The statistical analyses were performed using SAS 9.4 (SAS Institute Inc., Cary, NC, USA), with $p<0.05$ considered statistically significant. 


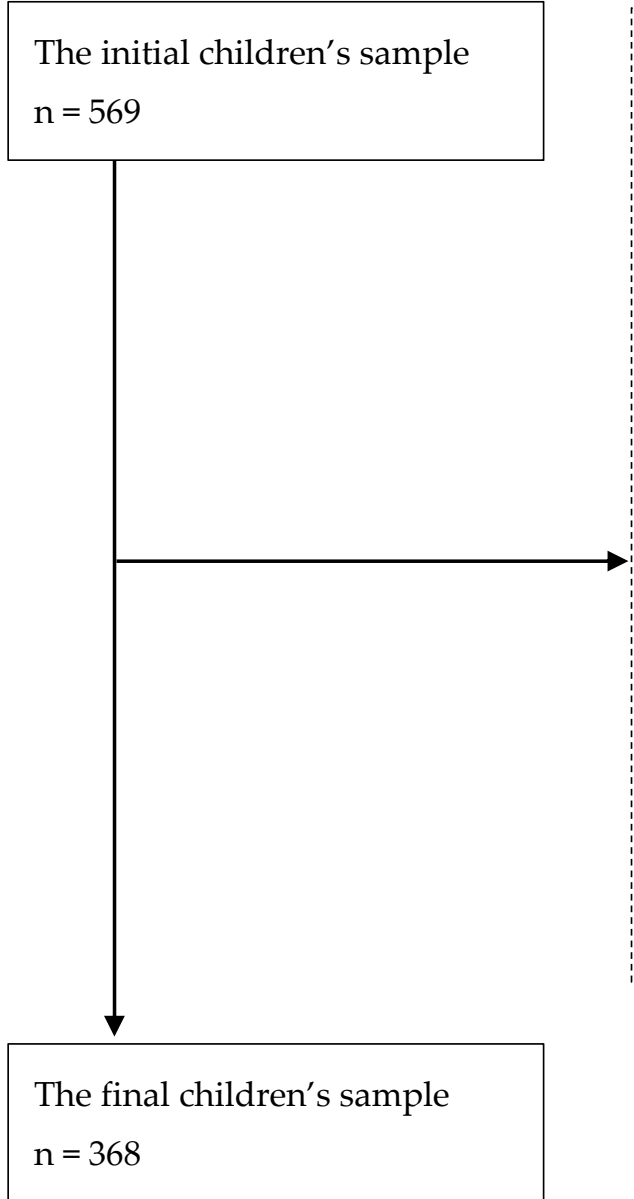

The excluded children

- Missing data including no accelerometer data by the criteria $(n=91)$

- Revocation of the consent $(\mathrm{n}=8)$

- History of conditions affecting physical activity $(\mathrm{n}=27)$

- No questionnaire data $(\mathrm{n}=16)$

- Different ethnic group $(\mathrm{n}=1)$

- Missing data including no accelerometer data by the criteria of parents $(n=40)$

- Revocation of the consent of parents $(n=2)$

- History of conditions affecting physical activity of parents $(\mathrm{n}=11)$

- No questionnaire data of parents $(n=4)$

- Pregnancy of the mother $(n=1)$

The initial parents' sample $\mathrm{n}=651$

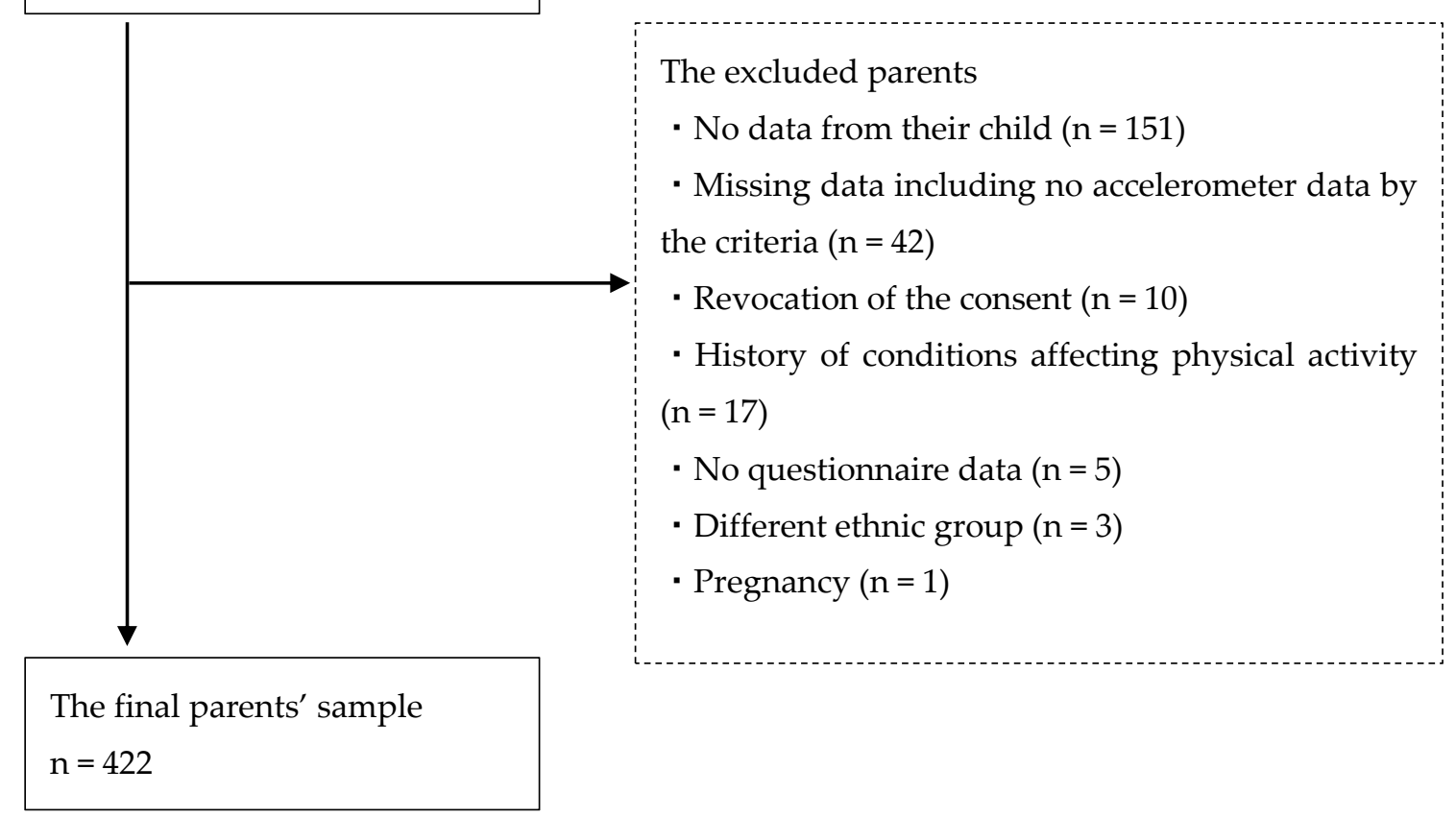

Figure 1. Flow of participants. 


\section{Results}

\subsection{Characteristics of the Study Participants}

The mean age of the mothers of the 148 boys was $41.0 \pm 4.2$ years and $42.5 \pm 4.9$ years for the fathers of the 58 boys, while the mean age of the mothers of the 173 girls was $41.3 \pm 3.9$ years and $43.6 \pm 4.7$ years for the fathers of the 65 girls. The characteristics of the children are summarized in Table 1 . Of the study participants, $13.3 \%$ of boys and $5.4 \%$ of girls were overweight/obese, while $2.4 \%$ of boys and $5.4 \%$ of girls were classified as thin. Times in ambulatory and non-ambulatory MVPA, and sedentary time were 2.7\% (SD 1.5\%), 3.4\% (SD 2.1\%), and 55.5\% (SD 8.8\%) for mothers, and $4.3 \%$ (SD 2.4), 1.8\% (SD 1.6\%), and 64.9\% (SD 11.1\%) for father, respectively. Out of 146 children (47.3\% of all children for parental support analysis) who answered their mother's work pattern by the questionnaires, 41 children had mothers with full-time work. The number of children who answered their father's work pattern by the questionnaires were $71(51.4 \%)$. All of their fathers worked full-time. One hundred and fifty-six children's mothers (51.0\%) and 111 children's fathers $(80.4 \%)$ answered weekend job duty. One hundred and one children's mothers and 69 children's father had no duty on weekends or no job. Mothers without a job were 117 from 287 (93.8\%) children who reported mother's occupation. Table 2 shows the results of parental support. There were no gender interactions in children. Objectively evaluated MVPA in children showed a significant positive association with maternal total MVPA $(p<0.001)$ and ambulatory MVPA $(p=0.001)$ after adjustment for the children's gender, grade, body mass index z-score, paternal or maternal age, and school (Table 3). Non-ambulatory MVPA in children showed a non-significant positive association with maternal non-ambulatory MVPA ( $p=0.062)$ (Table 3). On weekdays, objectively evaluated MVPA in children also correlated positively with maternal total MVPA $(p<0.001)$ and ambulatory MVPA $(p=0.007)$. On weekend days, objectively evaluated ambulatory MVPA in children correlated positively with maternal ambulatory MVPA $(p=0.030)$. Paternal or maternal sedentary time and paternal MVPA showed no association with either sedentary time or MVPA in children.

Table 1. Physical characteristics of the study participants, grouped according to age and sex.

\begin{tabular}{lc}
\hline Variables & Mean \pm SD \\
\hline Boys $(\mathrm{n}=166)$ & \\
Age (years) & $9.4 \pm 1.6$ \\
Body height $(\mathrm{cm})$ & $132.6 \pm 10.0$ \\
Body weight $(\mathrm{kg})$ & $29.8 \pm 8.0$ \\
Body mass index $\left(\mathrm{kg} / \mathrm{m}^{2}\right)$ & $16.7 \pm 2.6$ \\
Body mass index z-score & $-0.1 \pm 1.3$ \\
Sedentary time $(\%)$ & $46.0 \pm 6.9$ \\
Total moderate-to-vigorous physical activity (\%) & $9.6 \pm 2.5$ \\
Ambulatory moderate-to-vigorous physical activity (\%) & $5.9 \pm 1.9$ \\
Non-ambulatory moderate-to-vigorous physical activity (\%) & $3.7 \pm 1.1$ \\
Girls (n = 202) & \\
Age (years) & $9.4 \pm 1.6$ \\
Body height (cm) & $132.8 \pm 11.3$ \\
Body weight (kg) & $28.7 \pm 7.3$ \\
Body mass index (kg/m $\left.{ }^{2}\right)$ & $16.0 \pm 2.0$ \\
Body mass index z-score & $-0.2 \pm 1.1$ \\
Sedentary time $(\%)$ & $47.5 \pm 7.6$ \\
Total moderate-to-vigorous physical activity (\%) & $7.4 \pm 2.2$ \\
Ambulatory moderate-to-vigorous physical activity (\%) & $4.0 \pm 1.4$ \\
Non-ambulatory moderate-to-vigorous physical activity (\%) & $3.4 \pm 1.1$ \\
\hline
\end{tabular}


Table 2. Responses of children's' physical activity to parental support.

\begin{tabular}{|c|c|c|c|c|c|}
\hline Questions & & Mother & $\mathbf{N}$ & Father & $\mathbf{N}$ \\
\hline \multirow{2}{*}{ How much time do you spend with your child on weekdays? } & Low & Less than $5 \mathrm{~h}$ & 182 & Less than $1 \mathrm{~h}$ & 61 \\
\hline & High & More than $5 \mathrm{~h}$ & 120 & More than $1 \mathrm{~h}$ & 77 \\
\hline \multirow{2}{*}{ How much time do you spend with your child on weekends? } & Low & Less than $5 \mathrm{~h}$ & 30 & Less than $5 \mathrm{~h}$ & 45 \\
\hline & High & More than $5 \mathrm{~h}$ & 249 & More than $5 \mathrm{~h}$ & 89 \\
\hline \multirow{2}{*}{ How often do you encourage your child to be physically active? } & No & Rarely or Occasionally & 140 & & 115 \\
\hline & Yes & Often and Always & 161 & & 22 \\
\hline \multirow{2}{*}{ Do you watch your child's sporting events? } & No & Rarely or Occasionally & 135 & & 70 \\
\hline & Yes & Often and Always & 171 & & 65 \\
\hline \multirow{3}{*}{ Do you think that it is important for you to pay attention to sports? } & Unimportant & Unimportant & 24 & & 18 \\
\hline & Somewhat important & Somewhat important & 89 & & 34 \\
\hline & Important & $\begin{array}{l}\text { Important and Very } \\
\text { important }\end{array}$ & 189 & & 85 \\
\hline \multirow{2}{*}{ Does your family enjoy sports or physical activities as a family recreational activity? } & No & Rarely or Occasionally & 204 & & 100 \\
\hline & Yes & Often and Always & 102 & & 38 \\
\hline
\end{tabular}


Table 3. Associations between objectively evaluated physical activity and sedentary time of children and their mothers or fathers.

\begin{tabular}{cccccccc}
\hline Children & \multicolumn{3}{c}{ Mother $(\mathbf{n}=\mathbf{3 2 1})$} & \multicolumn{3}{c}{ Father $(\mathbf{n}=123)$} \\
\hline Variable & Coefficient & SE & $\boldsymbol{p}$-Value & Coefficient & SE & $\boldsymbol{p}$-Value \\
\hline Sedentary time (\%) & 0.056 & 0.043 & 0.200 & 0.116 & 0.056 & 0.175 \\
Total MVPA (\%) & 0.168 & 0.043 & $<0.001$ & 0.118 & 0.065 & 0.213 \\
Ambulatory MVPA (\%) & 0.207 & 0.060 & 0.001 & 0.043 & 0.059 & 0.545 \\
Non-Ambulatory MVPA (\%) & 0.053 & 0.028 & 0.062 & 0.195 & 0.063 & 0.090 \\
\hline
\end{tabular}

MVPA, moderate-to-vigorous physical activity. Mixed linear models were used to adjust for parent's age, child's age, gender, BMI z-score as fixed effects, and school as a random effect.

\subsection{Associations of Objectively Evaluated Physical Activity and Sedentary Time between Primary School} Children and Their Fathers or Mothers, and Parental Supports

The \%MVPA in children who spent more time with their mothers on weekends was significantly lower than that of children who spent less time with their mothers (difference between groups $=-0.901$; $p=0.034$ ) (Table 4). When limited to full-time working mothers or mothers without a job, there were no significant differences in \%MVPA of children $(\mathrm{n}=37$ : difference between groups $=-0.004 ; p=0.463$, $\mathrm{n}=110$ : difference between groups $=-1.051 ; p=0.111$, respectively). Children whose mothers watched their children's sports events had a significantly higher \%MVPA than those whose mothers did not watch these events (difference between groups $=0.720 ; p=0.009$ ). There were no significant differences in \%MVPA of children, when limited to full-time working mothers (difference betweenhigh and low groups $=0.398 ; p=0.640$ ) or mothers without a job (effect size $=0.532 ; p=0.209$ ). On the other hand, as shown in Table 5 children who spent time with their mothers on weekends had a significantly longer \%sedentary time than that of children who spent less time with their mothers $(47.0 \%$ vs. $44.4 \%$, difference between groups $=2.540 ; p=0.037$ ). The difference increased when limited to full-time working mothers (difference between groups $=2.5898, p=0.740$ ) or mothers without a job (difference between groups $=4.698 ; p=0.031$ ). There were no significant associations between MVPA or sedentary time of the children and paternal support. There were no significant associations between MVPA of the children who spent more time with their fathers who had the day off on weekends ( $n=69$, difference between groups $=0.004, p=0.513$ ). Due to the small sample size, further detailed analyses were not performed for the other subgroups. 
Table 4. Associations between objectively evaluated children's total moderate-to-vigorous physical activity and parental support.

\begin{tabular}{|c|c|c|c|c|c|c|c|c|c|}
\hline \multirow[b]{2}{*}{ Questions } & & \multicolumn{4}{|c|}{ Mother } & \multicolumn{4}{|c|}{ Father } \\
\hline & & $\mathrm{n}$ & Least Square Mean & SE & $p$-Value & $\mathrm{n}$ & Least Square Mean & SE & $p$-Value \\
\hline \multirow{2}{*}{ How much time do you spend with your child on weekdays? } & High & 302 & 8.4 & 0.2 & 0.314 & 138 & 8.4 & 0.2 & 0.388 \\
\hline & Low & & 8.7 & 0.2 & & & 8.1 & 0.3 & \\
\hline \multirow{2}{*}{ How much time do you spend with your child on weekends? } & High & 279 & 8.4 & 0.2 & 0.034 & 134 & 8.4 & 0.2 & 0.516 \\
\hline & Low & & 9.3 & 0.4 & & & 8.1 & 0.3 & \\
\hline \multirow{2}{*}{ How often do you encourage your child to be physically active? } & Yes & 301 & 8.8 & 0.2 & 0.106 & 137 & 8.6 & 0.2 & 0.2652 \\
\hline & No & & 8.3 & 0.2 & & & 7.8 & 0.3 & \\
\hline \multirow{2}{*}{ Do you watch your child's sporting events? } & Yes & 306 & 8.9 & 0.2 & 0.008 & 135 & 8.5 & 0.3 & 0.557 \\
\hline & No & & 8.2 & 0.2 & & & 8.2 & 0.2 & \\
\hline \multirow{3}{*}{ Do you think that it is important for you to pay attention to sports? } & Unimportant & 302 & 7.8 & 0.5 & 0.492 & 137 & 7.5 & 0.5 & 0.464 \\
\hline & Somewhat important & & 8.7 & 0.3 & & & 8.6 & 0.4 & \\
\hline & Important & & 8.5 & 0.2 & & & 8.3 & 0.2 & \\
\hline \multirow{2}{*}{$\begin{array}{l}\text { Does your family enjoy sports or physical activities as a family } \\
\text { recreational activity? }\end{array}$} & Yes & 306 & 8.7 & 0.2 & 0.533 & 138 & 8.7 & 0.3 & 0.250 \\
\hline & No & & 8.5 & 0.2 & & & 8.1 & 0.2 & \\
\hline
\end{tabular}

Least square mean was adjusted for child's age, gender, BMI z-score as fixed effects, and school as a random effect.

Table 5. Associations between objectively evaluated children's sedentary time and parental support.

\begin{tabular}{|c|c|c|c|c|c|c|c|c|c|}
\hline \multirow{2}{*}{ Questions } & & \multicolumn{4}{|c|}{ Mother } & \multicolumn{4}{|c|}{ Father } \\
\hline & & n & Least Square Mean & SE & $p$-Value & $\mathbf{n}$ & Least Square Mean & SE & $p$-Value \\
\hline \multirow{2}{*}{ How much time do you spend with your child on weekdays? } & High & 302 & 47.1 & 0.7 & 0.380 & 138 & 46.1 & 0.8 & 0.663 \\
\hline & Low & & 46.4 & 0.6 & & & 46.6 & 0.8 & \\
\hline \multirow{2}{*}{ How much time do you spend with your child on weekends? } & High & 279 & 47.0 & 0.6 & 0.037 & 134 & 46.3 & 0.7 & 0.926 \\
\hline & Low & & 44.4 & 1.2 & & & 46.2 & 1.0 & \\
\hline \multirow{2}{*}{ How often do you encourage your child to be physically active? } & Yes & 301 & 46.7 & 0.7 & 0.726 & 137 & 45.7 & 0.7 & 0.409 \\
\hline & No & & 46.9 & 0.7 & & & 47.3 & 0.9 & \\
\hline \multirow{2}{*}{ Do you watch your child's sporting events? } & Yes & 306 & 46.1 & 0.6 & 0.055 & 135 & 46.6 & 0.8 & 0.566 \\
\hline & No & & 47.6 & 0.7 & & & 45.8 & 0.8 & \\
\hline \multirow{3}{*}{ Do you think that it is important for you to pay attention to sports? } & Unimportant & 302 & 47.0 & 1.3 & 0.409 & 137 & 46.7 & 1.6 & 0.591 \\
\hline & Somewhat important & & 47.3 & 0.8 & & & 44.9 & 1.2 & \\
\hline & Important & & 46.4 & 0.6 & & & 46.9 & 0.7 & \\
\hline \multirow{2}{*}{$\begin{array}{l}\text { Does your family enjoy sports or physical activities as a family } \\
\text { recreational activity? }\end{array}$} & Yes & 306 & 46.7 & 0.8 & 0.950 & 138 & 45.6 & 1.1 & 0.527 \\
\hline & No & & 46.7 & 0.6 & & & 46.6 & 0.7 & \\
\hline
\end{tabular}

Least square mean was adjusted for child's age, gender, BMI z-score as fixed effects, and school as a random effect. 


\section{Discussion}

The findings in this paper demonstrate that only a mother's MVPA was associated positively with their child's MVPA. The mother's sedentary time was not associated either positively or negatively with their child's sedentary time. This study also found positive associations between children's MVPA and maternal support. Conversely, children whose mothers spent time with them on weekends had a lower MVPA and higher sedentary time. There were no associations between children's MVPA or sedentary time and either paternal MVPA, sedentary time, or support.

The present study collected data between June 2012 and January 2015. In our previous study, significant seasonal variation in MVPA and sedentary time was found between spring season in the school year and summer season in the summer vacation [24]. However, there is no study of seasonal variation in PA and sedentary time among winter and spring or autumn seasons in Japan. The mean values of maximum temperatures in the present study were 18.0 (SD 2.4) degree in the spring season (April), 18.8 (SD 2.1) degree autumn season (from September to November), and 12.9 (SD 4.2) degree in the winter season (January) [25]. All measurements were conducted under moderate weather, without heavy rain or snow, storm, etc. Recently, Lewis et al. reported that daily maximum temperature was significantly associated with MVPA time in Australia and Canada [26]. MVPA time appears to be optimal when the maximum temperature ranges between 20 and $25{ }^{\circ} \mathrm{C}$ in both countries. Thus, the slight difference between seasons in 4 years would not largely affect the results of the present study. Moreover, measurements were performed in January for only 21 children and their parents. In addition, because effect of school has been statistically adjusted and measurements were performed in a few weeks in each school, the effect of season on the results would be minimum.

The findings of our study demonstrated no associations between paternal MVPA and sedentary time, or the sedentary time of mothers and their children. In contrast, a mother's MVPA showed a positive association with their child's MVPA. Previous studies have shown significant relationships between the activities of parents and their children, including both sedentary and MVPA $[6,9,11,27,28]$. However, not all these studies are in agreement [29]. Jago et al. [29] also reported there was a weak, but significant association between sedentary time in parents and children. In terms of parental gender, maternal and paternal sedentary time showed similar associations with child sedentary time [11], while the association with child MVPA was lower in fathers [11]. Fuemmeler et al. [6] also reported that the minutes of MVPA and sedentary time in mothers and fathers correlated positively with both child MVPA and sedentary time. These previous studies were in UK and USA [6,9,11,27-29]. Hallal et al. reported that physical inactivity in adults (15 years or older) in UK or Japan were higher than that of in USA [30]. The proportion of 13-15-year-old boys and girls not achieving 60 min per day of MVPA is similar both UK and USA, whereas there are no such data in Japan [30]. Thus, the difference in findings between these studies may be related to different PA conditions due to the different locations (Western countries vs. Japan). The sample sizes in previous studies were from 45 parents to 408, and the majority of parental participation were mothers. Compared to fathers, mothers seem to spend more time in non-ambulatory activities such as household work (e.g., dusting, vacuuming, dishwashing, and doing laundry) [31]. In addition, the NHK National Time Use Survey [32] reported that over $90 \%$ of Japanese women carry out housework on weekdays and weekends, whereas only $41 \%$ of men do such work on weekdays, $51 \%$ on Saturdays, and $56 \%$ on Sundays. As a result, women spend about $4 \mathrm{~h} 30$ min on housework each day, while men spend about 50 min on weekdays, $1 \mathrm{~h} 23$ min on Saturdays, and $1 \mathrm{~h} 33 \mathrm{~min}$ on Sundays. These data demonstrate that Japanese mothers may spend more time than Japanese fathers carrying out activities classified as either household or child-care. The present study showed maternal non-ambulatory activities (3.4\%) were higher than ambulatory activities (2.7\%), which was consistent with the previous study [31] with the opposite association being observed in fathers (non-ambulatory activities: $1.8 \%$ and ambulatory activities: $4.3 \%$ ). Gender differences in lifestyle characteristics may therefore affect maternal and paternal PA and sedentary time, which in turn may lead to an association with their children's PA and sedentary time. 
A recent longitudinal study in the UK found that parents who were more physically active when aged 8-9 years had relatively active children, although the magnitude of this association was generally small. Furthermore, changes in the PA of parents was found to be a weak predictor of changes in the PA of their child [11]. Simple strategies that focus on encouraging parents to be active together with their child are therefore unlikely to be sufficient to increase a child's PA [12]. Our data provides no evidence of an association between fathers' support and their child's MVPA or sedentary time although there were positive associations between maternal support of a child's sporting events and the child's MVPA. We showed that $44 \%$ of fathers spent less than $1 \mathrm{~h}$ with their child on weekdays, and even on weekends, only $35 \%$ of fathers spent more than $5 \mathrm{~h}$ with their child. During weekdays, in particular, fathers spent little or no time with their child. According to the NHK National Time Use Survey [32], the working hours of Japanese male jobholders in their 30s and 40s was more than $9 \mathrm{~h}$ on weekdays. Although $40 \%$ of mothers spent more than $5 \mathrm{~h}$ with their child on weekdays and $89 \%$ did so on weekends, the children's objectively evaluated MVPA during the weekend showed a negative association with the length of time the mothers spent with their child. On the other hand, the children's objectively evaluated sedentary time correlated positively with the sedentary time for mothers. As mentioned above, considering that over $90 \%$ of Japanese women carry out housework on weekdays and weekends and spend about $4 \mathrm{~h}, 30 \mathrm{~min}$ on housework each day according to the NHK National Time Use Survey [32], even if the mother and child spend time together, they might engage in more sedentary behavior than in active PA. The present study did not directly evaluate joint PA between parents and their children as we wanted to reduce parents' burden as participants. Dunton et al. [33] examined the locations of joint PA between parents and children using accelerometers and global positioning systems (GPS) devices. They found joint PA was spread across residential locations $(35 \%)$, commercial venues $(24 \%)$, and open spaces and parks $(20 \%)$. Because a mother's objectively measured MVPA was associated positively with their child's MVPA, future studies should examine the activities that mothers and their child carry out together.

As shown in Table 4, the only positive associations we observed were between maternal support of children's sporting events and the MVPA of children, despite the parental support of children's sporting events being similar between parents (mothers $55.9 \%$ vs. fathers $48.1 \%$ ). It might be a positive aspect to improve the MVPA of children. To our knowledge, only four studies in the US and UK [13-16] have examined the role of family factors in promoting PA and used the Activity-Related Parenting Practices Scale as a measure of parental support [34]. This scale consists of a seven-item scale with two sub-factors: logistic support (attending the activities with the child, three items) and explicit modeling (using PA as a family recreation, four items). Previous studies showed parental logistical support [14-16] or explicit modeling [13] was associated with the MVPA of their children. Forthofer et al. [17] also reported that mothers' support (4 items, encourage PA, play outside and do PA, provide transportation, and watch child be physically active) had modest positive associations with MVPA. The findings of the present study were consistent with some of these results, despite our study treating each of the items as a single factor. We also examined associations of MVPA and sedentary time between children and parental supports with parents' work pattern and jobs on Saturday or Sunday. However, there were no significant differences of \%MVPA and \%sedentary time, maybe due to the small sample size. Although the previous studies didn't report parental occupations, the different association between father or mother and their children may be mediated by parents' work pattern. It is also possible that the different findings we have described may actually be due to the different locations of the studies (UK vs. Japan), because a comparison study of leisure time and personal care time in full-time worker among OECD, those times were shortest in Japan [35]. In this regard, simple strategies that focus on parental support may not be sufficient to increase PA in children. Therefore, the importance of parental support should be emphasized in policy and intervention development for families with a non-full-time worker. Rather, we would argue that more work is needed to identify whether or not children with full-time worker parents have low PA. 
Previous studies also reported that parenting style was associated with children's PA [14-16]. For example, in a computer-assisted telephone interview survey in Ontario, parents reported more parent level and environmental level barriers to support child PA compared to other behaviors such as reducing recreational screen time, encouraging healthy eating, and ensuring good sleep habits [36]. We therefore propose that more studies on parenting style are needed to identify the relationship between parenting style and PA in children.

Several methodological points and limitations need to be considered when interpreting the results of this study. First, although the accelerometer is a widely used tool to measure PA, it does not provide information on the types of activities being performed or the physical environment in which the physical activities took place. Additional descriptive studies employing direct observational approaches to capture contextual PA and sedentary time information are therefore warranted. Second, the Activity-Related Parenting Practices Scale was used as a measure of parental support in the four previous studies we cited [13-16] and the validity has been examined [34], whereas the validity of the questions used in our study have not been examined. One point of difference between the Activity-Related Parenting Practices Scale and our questionnaire is that it analyzed logistical data as a whole not as individual questions, whereas we analyzed the results of each question separately for their association with PA and sedentary time of the children. Moreover, a question of a parent watching sports event is needed to pay attention, because parents cannot watch the sport if the child is not playing sport. Third, we cannot detect reasons of the results, because the children were not asked to complete their activity log sheets together with their parent during the measurement period. In the future study, log sheets, GPS, or both, will be needed to identify together with their mother and/or father. Fourth, almost $70 \%$ of the parents were female, which may bias the generalizability of our findings on parent-child associations. Our findings may therefore be more relevant to mother-child relationships. Previous studies have reported a similar issue $[28,37,38]$. The strengths of our study include the use of a sample population of Japanese primary school children and their parents with the data from both parents and children being collected on the same days within an Asian country. The sample size of our study was also larger than that of most earlier studies.

\section{Conclusions}

In conclusion, objectively evaluated MVPA in children correlated positively with maternal MVPA. However, paternal or maternal sedentary time and paternal MVPA did not correlate with sedentary time or MVPA in children. On the other hand, the percentage of MVPA (\%MVPA) in children who spent more time with their mothers on weekends was significantly lower than that of children who spent less time (\%MVPA, $8.4 \%$ vs. 9.3\%). Children whose mothers watched their sports events had a significantly higher \% MVPA than those whose mothers did not (\%MVPA, $8.9 \%$ vs. $8.2 \%$ ). There were no associations between children's MVPA and paternal support. The findings of this study demonstrate the significance of maternal MVPA and support to identifying determinants of activity behavior will help interventions to increase PA.

Author Contributions: Designed research, C.T. and S.T.; coordinated data collection, C.T. and M.T.; analyzed the data, M.O.; discussed the analysis and interpreted the results, C.T., M.O., S.I., and S.T.; wrote paper, C.T.; had primary responsibility of the final content, C.T. All authors reviewed the manuscript critically and approved the final manuscript.

Funding: Please add: This research was funded by a JSPS KAKENHI grant number 24500832.

Acknowledgments: The authors would like to thank the participants for their cooperation in the study. We also wish to thank the staff of the National Institute of Health and Nutrition for their help with the experiments.

Conflicts of Interest: The authors declare no conflict of interest. 


\section{References}

1. Poitras, V.J.; Gray, C.E.; Borghese, M.M.; Carson, V.; Chaput, J.P.; Janssen, I.; Katzmarzyk, P.T.; Pate, R.R.; Connor, G.S.; Kho, M.E.; et al. Systematic review of the relationships between objectively measured physical activity and health indicators in school-aged children and youth. Appl. Physiol. Nutr. Metab. 2016, 41 (Suppl. S3), S197-S239. [CrossRef]

2. Carson, V.; Hunter, S.; Kuzik, N.; Gray, C.E.; Poitras, V.J.; Chaput, J.P.; Saunders, T.J.; Katzmarzyk, P.T.; Okely, A.D.; Connor, G.S.; et al. Systematic review of sedentary behaviour and health indicators in school-aged children and youth: An update. Appl. Physiol. Nutr. Metab. 2016, 41 (Suppl. S3), S240-S265. [CrossRef]

3. Saunders, T.J.; Gray, C.E.; Poitras, V.J.; Chaput, J.P.; Janssen, I.; Katzmarzyk, P.T.; Olds, T.; Connor, G.S.; Kho, M.E.; Sampson, M.; et al. Combinations of physical activity sedentary behaviour and sleep: Relationships with health indicators in school-aged children and youth. Appl. Physiol. Nutr. Metab. 2016, 41 (Suppl. 3), S283-S293. [CrossRef]

4. Tanaka, C.; Reilly, J.J.; Huang, W.Y. Longitudinal changes in objectively measured sedentary behaviour and their relationship with adiposity in children and adolescents: Systematic review and evidence appraisal. Obes. Rev. 2014, 15, 791-803. [CrossRef] [PubMed]

5. Jago, R.; Solomon-Moore, E.; Macdonald-Wallis, C.; Sebire, S.J.; Thompson, J.L.; Lawlor, D.A. Change in children's physical activity and sedentary time between Year 1 and Year 4 of primary school in the B.-PROACT1V cohort. Int. J. Behav. Nutr. Phys. Act. 2017, 14, 33. [CrossRef] [PubMed]

6. Fuemmeler, B.F.; Anderson, C.B.; Mâsse, L.C. Parent-child relationship of directly measured physical activity. Int. J. Behav. Nutr. Phys. Act. 2011, 8, 17. [CrossRef] [PubMed]

7. Hnatiuk, J.A.; DeDecker, E.; Hesketh, K.D.; Cardon, G. Maternal-child co-participation in physical activity-related behaviours: Prevalence and cross-sectional associations with mothers and children's objectively assessed physical activity levels. BMC Public Health 2017, 17, 506. [CrossRef] [PubMed]

8. Uijtdewilligen, L.; Brown, H.E.; Müller, R.F.; Lim, Y.W.; Brage, S.; van Sluijs, E.M. A systematic review of methods to measure family co-participation in physical activity. Obes. Rev. 2017, 18, 1454-1472. [CrossRef] [PubMed]

9. McMurray, R.G.; Berry, D.C.; Schwartz, T.A.; Hall, E.G.; Neal, M.N.; Li, S.; Lam, D. Relationships of physical activity and sedentary time in obese parent-child dyads: A cross-sectional study. BMC Public Health 2016, 16, 124. [CrossRef] [PubMed]

10. Neshteruk, C.D.; Nezami, B.T.; Nino-Tapias, G.; Davison, K.K.; Ward, D.S. The influence of fathers on children's physical activity: A review of the literature from 2009 to 2015. Prev. Med. 2017, 102, 12-19. [CrossRef] [PubMed]

11. Jago, R.; Solomon-Moore, E.; Macdonald-Wallis, C.; Thompson, J.L.; Lawlor, D.A.; Sebire, S.J. Association of parents' and children's physical activity and sedentary time in Year 4 (8-9) and change between Year 1 (5-6) and Year 4: A longitudinal study. Int. J. Behav. Nutr. Phys. Act. 2017, 14, 110. [CrossRef] [PubMed]

12. Thompson, J.L.; Jago, R.; Brockman, R.; Cartwright, K.; Page, A.S.; Fox, K.R. Physically active families-de-bunking the myth? A qualitative study of family participation in physical activity. Child Care Health Dev. 2010, 36, 265-274. [CrossRef] [PubMed]

13. Edwardson, C.L.; Gorely, T. Activity-related parenting practices and children's objectively measured physical activity. Pediatr. Exerc. Sci. 2010, 22, 105-113. [CrossRef] [PubMed]

14. Hennessy, E.; Hughes, S.O.; Goldberg, J.P.; Hyatt, R.R.; Economos, C.D. Parent-child interactions and objectively measured child physical activity: A cross-sectional study. Int. J. Behav. Nutr. Phys. Act. 2010, 7, 71. [CrossRef] [PubMed]

15. Jago, R.; Davison, K.K.; Brockman, R.; Page, A.S.; Thompson, J.L.; Fox, K.R. Parenting styles, parenting practices, and physical activity in 10- to 11-year olds. Prev. Med. 2011, 52, 44-47. [CrossRef] [PubMed]

16. O'Connor, T.M.; Chen, T.A.; Baranowski, J.; Thompson, D.; Baranowski, T. Physical activity and screen-media-related parenting practices have different associations with children's objectively measured physical activity. Child. Obes. 2013, 9, 446-453. [CrossRef] [PubMed] 
17. Forthofer, M.; Dowda, M.; McIver, K.; Barr-Anderson, D.J.; Pate, R. Associations between Maternal Support and Physical Activity Among 5th Grade Students. Matern. Child Health J. 2016, 20, 720-729. [CrossRef] [PubMed]

18. Oshima, Y.; Kawaguchi, K.; Tanaka, S.; Ohkawara, K.; Hikihara, Y.; Ishikawa-Takata, K.; Tabata, I. Classifying household and locomotive activities using a triaxial accelerometer. Gait Posture 2010, 31, 370-374. [CrossRef] [PubMed]

19. Ohkawara, K.; Oshima, Y.; Hikihara, Y.; Ishikawa-Takata, K.; Tabata, I.; Tanaka, S. Real-time estimation of daily physical activity intensity by a triaxial accelerometer and a gravity-removal classification algorithm. Br. J. Nutr. 2011, 105, 1681-1691. [CrossRef] [PubMed]

20. Hikihara, Y.; Tanaka, C.; Oshima, Y.; Ohkawara, K.; Ishikawa-Takata, K.; Tanaka, S. Prediction models discriminating between nonlocomotive and locomotive activities in children using a triaxial accelerometer with a gravity-removal physical activity classification algorithm. PLoS ONE 2014. [CrossRef] [PubMed]

21. Trost, S.G.; McIver, K.L.; Pate, R.R. Conducting accelerometer-based activity assessments in field-based research. Med. Sci. Sports Exerc. 2005, 37, S531-S543. [CrossRef] [PubMed]

22. Cole, T.J.; Green, P.J. Smoothing centile curves: The LMS method and penalized likelihood. Stat. Med. 1992, 11, 1305-1319. [CrossRef] [PubMed]

23. Inokuchi, M.; Hasegawa, T.; Anzo, M.; Matsuo, N. Standardized centile curves of body mass index for Japanese children and adolescents based on the 1978-1981 national survey data. Ann. Hum. Biol. 2006, 33, 444-453. [CrossRef] [PubMed]

24. Tanaka, C.; Reilly, J.J.; Tanaka, M.; Tanaka, S. Seasonal changes in objectively measured sedentary behavior and physical activity in Japanese primary school children. BMC Public Health 2016, 16, 969. [CrossRef] [PubMed]

25. Japan Meteorological Agency. Available online: http://www.jma.go.jp/jma/indexe.html (accessed on 18 August 2018).

26. Lewis, L.K.; Maher, C.; Belanger, K.; Tremblay, M.; Chaput, J.P.; Olds, T. At the mercy of the gods: Associations between weather, physical activity, and sedentary time in children. Pediatr. Exerc. Sci. 2016, 28, 152-163. [CrossRef] [PubMed]

27. Olvera, N.; Smith, D.W.; Lee, C.; Liu, J.; Lee, J.; Kim, J.H.; Kellam, S.F. Comparing high and low acculturated mothers and physical activity in Hispanic children. J. Phys. Act. Health 2011, 8 (Suppl. S2), S206-S213. [CrossRef]

28. Bauer, K.W.; Neumark-Sztaine, S.D.; Fulkerson, J.A.; Hannan, P.J.; Story, M. Familial correlates of adolescent girls' physical activity, television use, dietary intake, weight, and body composition. Int. J. Behav. Nutr. Phys. Act. 2011, 8, 25. [CrossRef] [PubMed]

29. Jago, R.; Fox, K.R.; Page, A.S.; Brockman, R.; Thompson, J.L. Parent and child physical activity and sedentary time: Do active parents foster active children? BMC Public Health 2010, 10, 194. [CrossRef] [PubMed]

30. Hallal, P.C.; Andersen, L.B.; Bull, F.C.; Guthold, R.; Haskell, W.; Ekelund, U.; Lancet Physical Activity Series Working Group. Global physical activity levels: Surveillance progress, pitfalls, and prospects. Lancet 2012, 380, 247-257. [CrossRef]

31. Tanaka, C.; Fujiwara, Y.; Sakurai, R.; Fukaya, T.; Yasunaga, M.; Tanaka, S. Locomotive and non-locomotive activities evaluated with a triaxial accelerometer in adults and elderly individuals. Aging Clin. Exp. Res. 2013, 25, 637-643. [CrossRef] [PubMed]

32. Kobayashi, T.; Morofuji, E.; Watanabe, Y. Sleeping Time Keeps Decreasing, Male Housework Time is Increasing. From the 2010 NHK Japanese Time Use Survey. Available online: http://www.nhk.or.jp/ bunken/english/reports/pdf/report_110401.pdf (accessed on 4 May 2013).

33. Dunton, G.F.; Liao, Y.; Almanza, E.; Jerrett, M.; Spruijt-Metz, D.; Pentz, M.A. Locations of joint physical activity in parent-child pairs based on accelerometer and GPS monitoring. Ann. Behav. Med. 2013, 45 (Suppl. 1), S162-S172. [CrossRef]

34. Davison, K.; Cutting, T.; Birch, L. Parent's activity-related parenting practices predict girls' physical activity. Med. Sci. Sports Exerc. 2003, 35, 1589-1595. [PubMed] 
35. OECD. How's Life? Measuring Well-Being; OECD Publishing: Paris, France, 2011; Available online: http:/ / dx.doi.org/10.1787/9789264121164-en (accessed on 15 August 2018).

36. Jarvis, J.W.; Harrington, D.W.; Manson, H. Exploring parent-reported barriers to supporting their child's health behaviors: A cross-sectional study. Int. J. Behav. Nutr. Phys. Act. 2017, 14, 77. [CrossRef] [PubMed]

37. Cleland, V.; Timperio, A.; Salmon, J.; Hume, C.; Telford, A.; Crawford, D. A longitudinal study of the family physical activity environment and physical activity among youth. Am. J. Health Promot. 2011, 25, 159-167. [CrossRef] [PubMed]

38. Oliver, M.; Schofield, G.M.; Schluter, P.J. Parent influences on preschoolers' objectively assessed physical activity. J. Sci. Med. Sport 2010, 13, 403-409. [CrossRef] [PubMed]

(C) 2018 by the authors. Licensee MDPI, Basel, Switzerland. This article is an open access article distributed under the terms and conditions of the Creative Commons Attribution (CC BY) license (http://creativecommons.org/licenses/by/4.0/). 